\title{
Preproenkephalin Messenger RNA-containing Neurons in Striatum of Patients with Symptomatic and Presymptomatic Huntington's Disease: An In Situ Hybridization Study
}

\author{
Roger L. Albin, MD,* Ying Qin, MS,† Anne B. Young, MD, PhD,* John B. Penney, MD,* \\ and Marie-Francoise Chesselet, MD, PhD'-
}

\begin{abstract}
Previous studies have revealed a loss of enkephalin immunoreactivity in the terminals of striatal neurons projecting to the external globus pallidus in patients with early grades of Huntington's disease (HD). To assess the status of the perikarya of striatal enkephalinergic neurons, we performed in situ hybridization histochemistry with a radiolabeled RNA probe complementary to preproenkephalin messenger RNA. We studied postmortem brain tissue of 6 patients with symptomatic HD, 7 control subjects, and 2 presymptomatic carriers of the HD allele. There was a significant reduction in the areal density of striatal neurons expressing preproenkephalin messenger RNA in the patients with symptomatic HD, but the level of labeling in the remaining cells was not altered compared with the control subjects. In the specimens from presymptomatic individuals, there was no reduction of areal density of preproenkephalin messenger RNA-containing neurons in the striatum, despite the fact that loss of enkephalin immunoreactivity in the external globus pallidus had been previously demonstrated in the same brains. The results correlate with the previous demonstration of depleted enkephalin immunoreactive terminals in the external globus pallidus in patients with symptomatic HD. They also suggest that the early loss of enkephalin immunoreactivity observed in the external globus pallidus of presymptomatic carriers of the HD allele is not related to a generalized death of striatal enkephalinergic neurons early in the course of the disease.
\end{abstract}

Albin RL, Qin Y, Young AB, Penncy JB, Chcsselct M-F. Preproenkephalin messenger RNA-containing neurons in striatum of patients with symptomatic and presymptomatic Huntington's disease: an in situ hybridization study. Ann Neurol 1991;30:542-549

Striatal atrophy, especially of the caudate nucleus, is the histological signature of Huntington's disease (HD). Within the striatum, however, there is differential loss of subpopulations of neurons. Striatal neurons containing the neuropeptides somatostatin and neuropeptide $\mathrm{Y}$ and the enzyme NADPH-diaphorase, appear relatively spared in patients with $H D[1,2]$. The perikarya of striatal cholinergic interneurons also appear spared despite an impressive loss of striatal choline acetyltransferase levels [3-5]. These striatal interneuron pools represent only a small fraction of the neurons within the striatum. The great majority of striatal neurons are projection neurons and these striatal projection neurons are subdivided into different populations on the basis of their anatomical connectivity and neuropeptide content [6-11]. Striatal neurons projecting to the external globus pallidus ( $\mathrm{GPe}$ ) contain enkephalin (ENK), whereas those striatal neurons projecting to the internal globus pallidus (GPi) contain mostly tachykinins (SP: substance $\mathrm{P}$ and $\mathrm{K}$ ) $[12,13]$.

Immunohistochemical studies suggest that striatal projection neurons are differentially affected in the course of HD. We have found a decrease in ENK immunoreactivity in the GPe and of SP immunoreactivity in the substantia nigra pars reticulata in patients with early grades of HD [14]. Remarkably, this was also observed in probable presympromatic carriers of the HD allele [15]. In contrast, SP immunoreactivity in the GPi is preserved until relatively late in the course of the disease, suggesring that striato-GPi neu-
From the Department of Neurology, University of Michigan, Ann Arbor, MI, and †Department of Pharmacology, University of Pennsylvania, Philadelphia, PA.

Received Jan 11, 1991, and in revised form Mar 18. Accepted for publication Mar 25, 1991.
Address correspondence to Dr Chesselet, Department of Pharmacology, University of Pennsylvania, 36 and Hamilton Walk, Philardelphia, PA 19104. 
rons are relatively spared in patients with early grades of HD ([14]; for different results see [16]).

Perikarya of striatal neurons are difficult to visualize with immunohistochemistry without intracerebral colchicine treatment, a technique not applicable to humans. To test the hypothesis that the perikarya of striato-GPe projection neurons are affected early in the course of $\mathrm{HD}$, we used in situ hybridization histochemistry with an RNA probe for preproenkephalin messenger RNA (PPE mRNA) to determine if the perikarya of striatal ENK-containing neurons were depleted in brains from patients with early grades of HD.

\section{Material and Methods \\ Subjects}

We studied specimens from 6 patients with pathologically verified HD (grades 2-4), 7 control subjects, and 2 asymptomatic individuals who have been shown with very high probability, by linkage analysis, to be carriers of the HD allele. All patients were pathologically graded according to the criteria of Vonsartel and colleagues [17]. There was one grade 4, two grade 3, and three grade $2 \mathrm{HD}$ specimens. The presymptomatic HD allele carriers had normal neuropathological examinations. In particular, they did not show any striatal atrophy. Their HD allele status has been established by restriction fragment length polymorphism analysis with a degree of confidence of 95\% for Patient 1 [15] and $97 \%$ for Patient 2 (R. Albin, unpublished data).

Brains were obtained at autopsy, and one hemisphere was either frozen whole and stored at $-70^{\circ} \mathrm{C}$ before subsequent sectioning or sectioned into $1-\mathrm{cm}$ slabs in a coronal plane, and the slabs frozen in crushed dry ice before storage at $-70^{\circ} \mathrm{C}$. The average postmortem delay for HD specimens (excluding the presymptomatic carriers) was 16 hours (range, 6-24 hours), the average age of patients with HD was 58 years (range, 12-87 years). For control subjects, the equivalent numbers were 17 hours (range, 11-23 hours) for postmortem delay and 50 years (range, 23-81 years) for age. The average postmortem delay of the presymptomatic specimens was 25 hours, and the average age was 30 years. The number of years of storage of frozen specimens was 3.3 years for tissue from patients with $\mathrm{HD}, 2.4$ years for control subjects, and 3.5 years for presymptomatic carriers. Some of the patients with HD were receiving neuroleptic medication. Several of the specimens, including both presymptomatic HD allele carriers, one of the grade 2 specimens, one of the grade 3 specimens, and the grade 4 specimen had been previously studied with immunohistochemistry to examine the density of ENK immunoreactivity in the GPe [14, 15].

\section{In Situ Hybridization Histochemistry}

PREPARATION OF THE TISSUE. Blocks containing either head of the caudate nucleus (all control subjects, all patients with $\mathrm{HD}$, and 1 presymptomatic $\mathrm{HD}$ carrier) or putamen at the level of the pallidum (1 presymptomatic carrier) were equilibrated at $-20^{\circ} \mathrm{C}$ in a Reichert cryostat. Twelve-micron sections were cut on the cryostat and rapidly thaw-mounted onto gelatin-coated slides (see [18]). After mounting the sections, the slides were stored at $-70^{\circ} \mathrm{C}$ until the time of assay.
SYNTHESIS OF THE RADIOLABELED RNA PROBES. The radiolabeled complementary RNA (cRNA) probes were transcribed in vitro from a complementary DNA (CDNA) clone for PPE generously given by $\operatorname{Dr} \mathrm{S}$. Sabol of the National Institute of Mental Health [19]. The 935 base pairs cDNAs inserted into the transcription vector PSP64 and PSP65 (Promega Corp, Madison, WI) were linearized according to standard protocols [20] and used to transcribe antisense and sense cRNA probes, respectively. The specificity of the cDNA has been assessed previously by Northern analysis [19]. Similar cRNA probes have given specific hybridization signal in in situ hybridization experiments in the rat [21]. Transcription was performed in the presence of $2.5 \mu \mathrm{M}$ of ${ }^{35} \mathrm{~S}$-UTP $(1,000 \mathrm{Ci} / \mathrm{mmol}$, New England Nuclear, Wilmington, DE) and $10 \mu \mathrm{m}$ of unlabeled UTP with ATP, CTP, and GTP in excess as described previously [18].

IN SITU HYBRIDIZATION AND RADIOAUTOGRAPHY. All solutions and buffers used were prepared with distilled water treated with diethylpyrocarbonate to inhibit RNase activity (DEPC; Sigma Chemical, St Louis, MO) and autoclaved. The brain sections were quickly dried at room temperature under an air flow and fixed by immersion into a solution of $3 \%$ paraformaldehyde in phosphate buffer containing DEPC $0.02 \%$. In situ hybridization histochemistry was performed as described previously $[18,22]$. Briefly, sections were acetylated, dehydrated, and incubated with 2.5 to $3 \mathrm{ng}$ (in a volume of $20 \mu \mathrm{l}$ ) of radiolabeled PPE cRNA (specific activity, $4 \times 10^{5} \mathrm{cpm} / \mathrm{ng}$ ) for 210 minutes in a convection oven at a temperature of $50^{\circ} \mathrm{C}$. Posthybridization washes were in $2 \times$ standard saline citrate (SSC) containing $50 \%$ formamide at $52^{\circ} \mathrm{C}$ for 5 and 20 minutes, in RNase A $(100 \mu \mathrm{g} / \mathrm{ml}$; Sigma) for 30 minutes at $37^{\circ} \mathrm{C}$, and in $2 \times \mathrm{SSC}$ containing $50 \%$ formamide for 5 minutes. Sections were kept overnight under mild agitation in $2 \times$ SSC containing $0.05 \%$ Triton $\mathrm{X}-100$ at room temperature, dehydrated in ethanol, delipidated in xylene, air dried, coated with Kodak NTB3 emulsion diluted $1: 1$ with $300 \mathrm{mM}$ ammonium acetate, air dried, and stored in light-tight boxes in the presence of desiccant. After 21 days of exposure, the sections were developed in Kodak D-19 for 3.5 minutes at $14^{\circ} \mathrm{C}$. The sections were lightly counterstained with hematoxylin and eosin and mounted with Eukitt mounting media (Calibrated Instruments, Ardsley, NY). Control sections were hybridized in parallel with a sense radiolabeled RNA probe (identical to the PPE mRNA) under the same conditions.

QUANTIFICATION OF THE LABEling. Two sections from each brain, processed in the same experiment and exposed for the same amount of time, were chosen for quantification in this study. The number of labeled cells and the intensity of labeling were measured by an investigator blind to the origin of the specimens. Two methods were used to determine the areal density of cells expressing PPE MRNA in the striatum. First, all labeled cells present in each section were counted by scanning the section with a $10 \times$ objective under dark-field illumination; second, the section was visualized on a monitor with the help of a video camera (Morphon system; see below). A computer-generated grid corresponding to $0.026 \mathrm{~mm}^{2}$ of the section was superimposed on each field and all the labeled cells in the grid were counted. This was 
done in a set of six adjacent frames (total surface area, 0.16 $\mathrm{mm}^{2}$ ) in four different, arbitrarily chosen areas of each section (two sections per brain). The mean areal densities of labeled cells were similar in the eight sets of six frames measured in each brain. The mean areal densities of PPE-labeled cells obtained with each method were calculated for each brain and expressed as the number of labeled cells per millimeters squared. Results from the two methods were in excellent agreement, and numerical values obtained with the second method are reported here.

The intensity of labeling over cells was quantified by measuring the surface area occupied by silver grains over samples of labeled cells in the striatum. To collect an unbiased sample of cells, the level of labeling over all labeled cells (determined as cells covered by 10 or more pixels per cell) present within twelve to twenty $0.026-\mathrm{mm}^{2}$ arbitrarily chosen frames was measured, so that a total of 100 cells was measured in each section, except for the one HD grade 4, in which a total of 34 cells was measured. This was accomplished with a Morphon image-analysis system (Philadelphia, PA) [23]. The analog video signal was converted to a digital image of $512 \times 480$ pixels. The tissue sections were observed under bright-field illumination with a $40 \times$ objective. Threshold illumination was adjusted to distinguish silver grains from background staining. For each cell, the area of grain occupancy was measured and expressed as a number of pixels. Under these conditions, there is a linear correlation between the number of pixels and the number of silver grains counted visually [23]. The average number of pixels per cell was calculated for each brain. Results obtained in patients with $\mathrm{HD}$ and control subjects were compared using a nonparametric MannWhitney rank sum test $[24]$.

\section{Results}

\section{Density of PPE mRNA Neurons in the Striatum}

Striatal neurons labeled for PPE mRNA were clearly visible in specimens from control subjects, patients with $H D$ grades 2 through 4 , and presymptomatic carriers (Figs $1 \mathrm{~A}-\mathrm{C}, 2 \mathrm{~A}-\mathrm{D}$ ). No labeling was present in control sections exposed to the sense probe (Fig 1D). The average areal density of striatal PPE mRNAcontaining neurons was lower in clinically diagnosed HD specimens than in control subjects (see Figs 1C, 3 ). The magnitude of the decrease in grades 2 and 3 , however, was offset by the existence of a significant shrinkage in these HD specimens. The grade 4 specimen had very few PPE mRNA-containing striatal neurons at a grade when most striatal neurons have degenerated.

In specimens from the two presymptomatic carriers, the density of striatal PPE mRNA-containing neurons was within the range of control subjects (see Fig 3), even though previous immunohistochemical studies of the same brains have shown substantial reduction of ENK-immunoreactive terminals within the GPe. A relative dissociation of in situ hybridization and immunohistochemical results also exists for one of grade 2 and one grade 3 specimens. In these brains, we have pre- viously observed near total depletion of GPe ENKimmunoreactive striatal terminals, whereas the present in situ results indicate the presence of a sizable number of PPE mRNA-containing striatal neurons (103.1 and 94.6 PPE mRNA-expressing cells per millimeter squared, respectively).

\section{Density of Labeling of PPE}

$m R N A$-containing Neurons

Including the grade 4 brain, the average level of labeling per cell was very similar for all specimens examined (see Figs 2, 4). Thus, no statistical difference was found between level of labeling in brains from control subjects, presymptomatic carriers, or patients with grades 2 through $4 \mathrm{HD}$. No correlation was found between level of labeling of individual cells and postmortem delay or age of the patients. It should be noted, however, that the autoradiographic conditions (exposure time) were chosen to ensure visualization of the majority of striatal cells expressing PPE mRNA, resulting in very dense cellular labeling (see Fig 2). Quantification of individual labeling is not optimal under these conditions [23]. Subtle differences in the level of labeling may therefore have gone undetected. The results, however, clearly suggest that high level of expression of PPE mRNA is still present in remaining striatal neurons of patients with grades 0 through $4 \mathrm{HD}$.

\section{Discussion}

Our in situ hybridization data confirm the loss of striatal enkephalinergic neurons documented previously with immunohistochemical techniques in patients with grades 2 through $4 \mathrm{HD}[14,25]$. The present in situ hybridization results probably underestimate the degree of enkephalinergic neuron depletion because we measured the areal density of PPE mRNA-containing striatal neurons, which will be elevated in higher grade of HD due to striatal atrophy. With this in mind, there is a correlation between the degree of striatal neuro-

Fig 1. (A-C) Dark-field photomicrograpbs of sections from postmortem buman brain processed for in situ bybridization bistocbemistry with a ${ }^{35} S$-radiolabeled RNA probe complementary to preproenkephalin messenger RNA. (A) Section from a control brain. Note the bigh number of densely labeled cells (examples at arrows) identified by clusters of silver grains (white dots). (B) Section from a presymptomatic carrier of Huntington's disease (HD) allele (Patient 2). Note that the areal density of labeled cells (one at arrow) is similar to that of the control subject (A). (C) Section from a patient with grade $3 \mathrm{HD}$. Labeled cells are much less numerous, but still intensely labeled (example at arrow). (D) Dark-field pbotomicrograph of a section from a control brain, serially adjacent to that illustrated in A, bybridized with a sense (control) probe. Note the absence of specific labeling. Scale bar $=100 \mu \mathrm{m}$. 

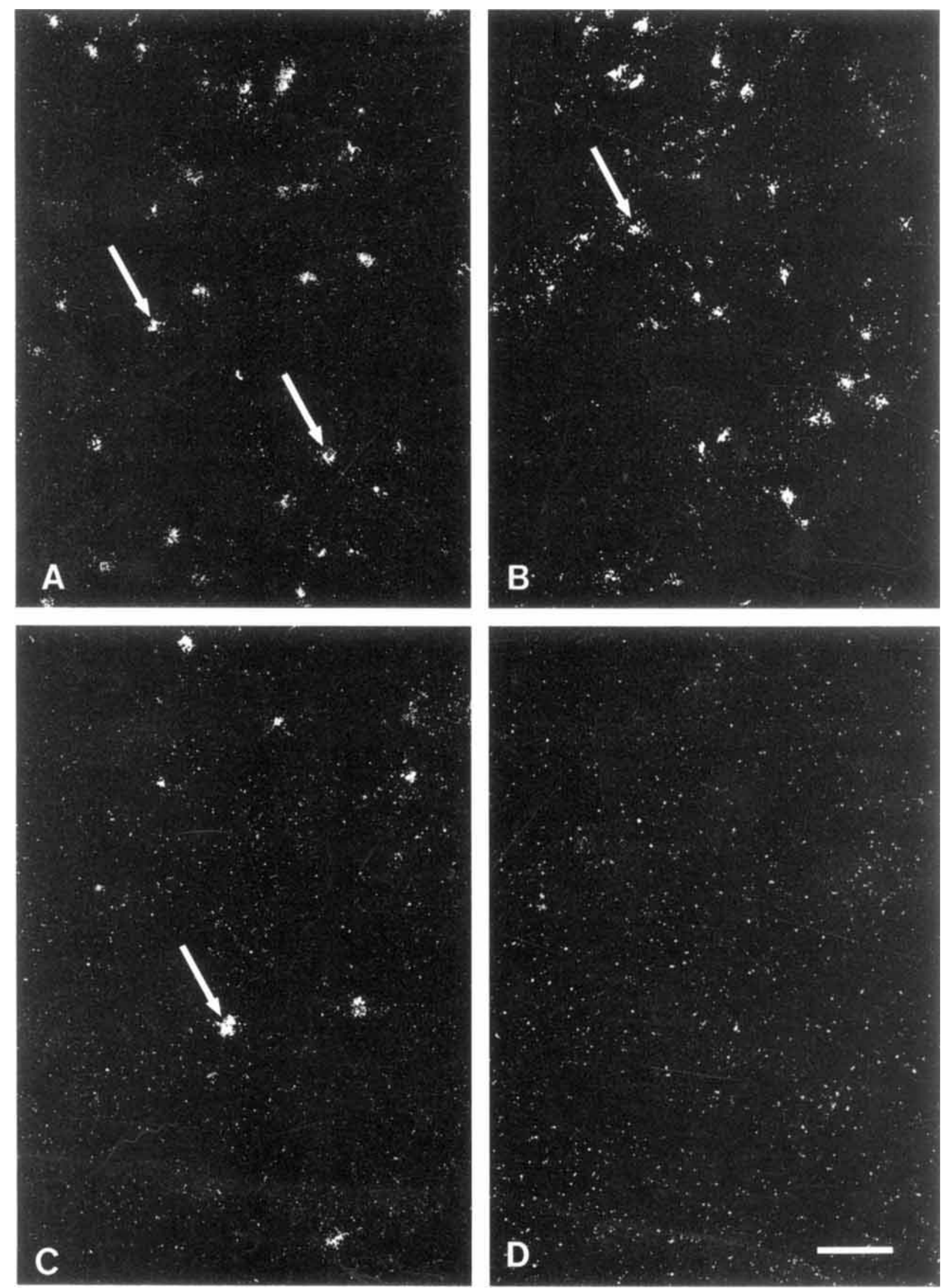

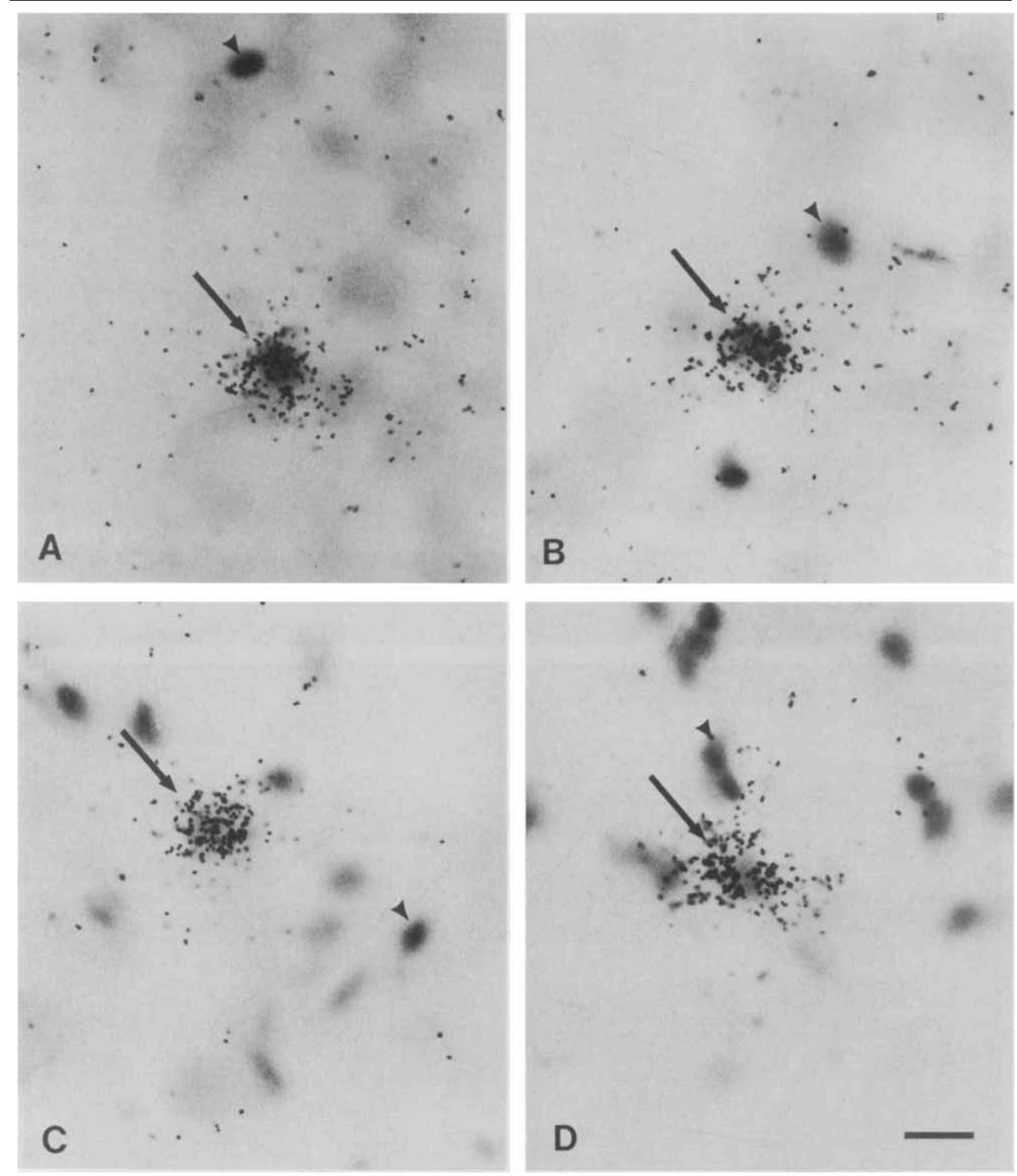

Fig 2. Bright-field photomicrographs of neurons expressing preproenkepbalin messenger RNA in buman striatum. Sections were processed as for Figure 1. Labeled cells (arrows) are characterized by the presence of dense clusters of silver grains in the overlaying emulsion. Note the low autoradiographic background and the presence of unlabeled glial cells (some at arrowheads).

(A) Section from a control subject, also illustrated in Figure $1 A$. (B) Section from presymptomatic Patient 2, also illustrated in Figure $1 B$. (C) Section from a patient with grade 3 Huntington's disease (HD). (D) Section from a patient with grade 3 $H D$ also illustrated in Figure 1 C. Scale bar $=10 \mu \mathrm{m}$. 


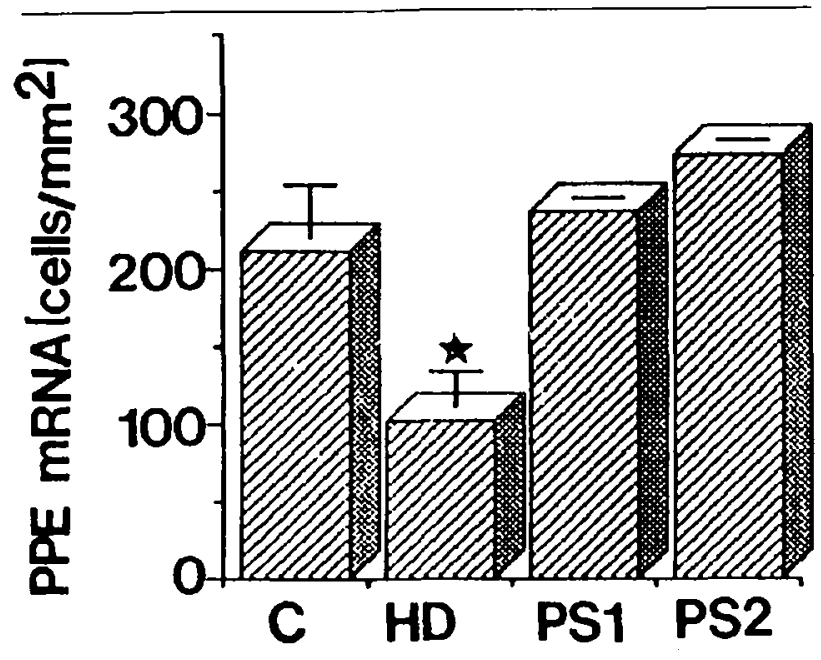

Fig 3. A real density of preproenkephalin messenger RNA-expressing cells in human striatum. Sections have been processed and data quantified as indicated in Subjects and Methods. Data for $C$ and $H D$ are mean $+S E M$ of average values ubtained in each individual. $C=$ control subjects $(n=7) ; H D$ $=$ patients with symptomatic Huntington disease, grades $2-4$ $(n=6): P S 1$ and PS2 = average values obtained in presymptomatic carriers of $H D$ allele (Patients 1 and 2, respectively). "p - 0.011 with a Mann-Whitney $\mathrm{U}$ test.

nal loss as determined by pathological grade and the degree of PPE mRNA-containing neuron depletion, with the grade 2 specimen having a higher density of PPE mRNA-containing neurons than the grade 4 specimen. Similarly, the normal density of PPE $\mathrm{mRNA}-\mathrm{containing} \mathrm{neurons} \mathrm{observed} \mathrm{in} \mathrm{presymptom-}$ atic carricrs of the HD allele parallels the absence of major loss of neurons in the striatum.

The decreased number and density of perikarya expressing PPE mRNA in the striata of patients with symptomatic HD is likely to explain the decrease in ENK immmunoreactivity in GPe of patients with grades 2 through $4 \mathrm{HD}$ [14]. The normal number of labeled neurons observed in presymptomatic patients, however, sharply contrasts with the results of previous immunohistochemical studies, which showed a loss of ENK immunoreactivity in the GPe in these presymptomatic carriers ([15] and R. Albin, unpublished results). Because only discrete regions of the striatum were examined, our results do not rule out the existence of a selective loss of enkephalinergic neurons in some parts of the striatum that were not contained in the samples studied here. This could occur, for example, in the dorsomedial region of the caudate nucleus, which shows early signs of cell loss in parients with $\mathrm{HD}$, and in which cell loss has been recorded in patients with grade $0 \mathrm{HD}$ [17]. Such localized cell death, however, would not be sufficient to account for the loss of ENK immunoreactivity observed in the GPe of

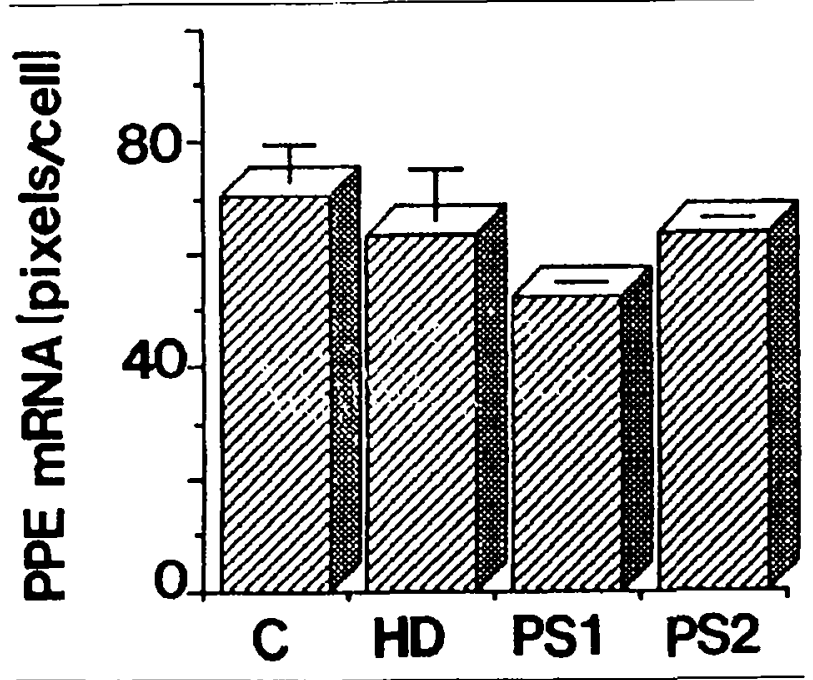

Fig 4. Intensity of labeling (pixels per cell) of preproenkephalin messenger RNA-expressing cells in buman striatum. Sections were processed and results quantified as described in Subjects and Methods. Data for $C$ and $H D$ are mean $+S E M$ of average value obtained in each individual. $C=$ control subjects (n $=71: H D=$ patients with symptomatic Huntington's disease, grades 2-4 $(n=6) ; P S 1$ and PS2 = presymptomatic carriers of the HD allele (Patients $l$ and 2 , respectively).

these individuals. The areas examined in this study (head of caudate nucleus for Patient 2 and middle of putamen for Patient 1) correspond to areas shown in nonhuman primates to project to the area of GPe showing loss of ENK immunoreactivity in these patients $[7,8,10,11,26]$.

Discrepancy between the loss of a marker of nerve terminal integrity and survival of perikarya has been secn previously in both patients with HD and patients with Alzheimer's disease. Biochemical studies demonstrating loss of choline acetyltransferase activity led to the conclusion that striatal cholinergic interneurons degenerate in patients with $\mathrm{HD}[5,27]$. More recent studies with acetylcholinesterase histochemistry and immunohistochemistry with antisera directed against choline acetyltransferase have shown preservation of the perikarya of striatal cholinergic neurons in patients with HD [3, 4]. Similarly, in patients with Alzheimcr's disease, a severe reduction in neocortical choline acetyltransferase activity is not always accompanied by loss of basal forebrain neurons giving rise to the cholinergic afferents of the neocortex [28].

The dissociation between the present in situ hybridization results and immunohistochemistry in the presymptomatic specimens could be related to a defect in the regulation of ENK metabolism. Defects could exist in translation, posttranslational modifications, and perikaryal processing of the translated protein, or there could be enhanced turnover of the final peptide. Other 
alternatives would be deficient transport of the final peptide or its precursors from the perikaryon to the axon terminal or degeneration of axon terminals in the $\mathrm{GPe}$. There is a previous suggestion of abnormal regulation of neuropeptide production in patients with HD. Beal and co-workers [29] have shown that somatostatin levels are increased in early grade HD specimens where striatal atrophy is minimal, suggesting that elevated somatostatin concentration is not due to concentrative effects secondary to atrophy.

The level of labeling for PPE mRNA per cell was not different in HD (grades 0-4) compared with control specimen. Even in the one grade 4 brain examined, labeling in the rare remaining cells was intense, with most of the values within the range of the control subjects. Several of the patients with HD were treated with neuroleptics, and haloperidol treatment in rats increases PPE mRNA levels in striatum $[30,31]$. Neurolepric stimulation of PPE mRNA is unlikely to explain our results because, in experimental animals, the stimulatory effects of haloperidol are no longer seen after 4 weeks of continuous treatment [21]. Intensely labeled cells were found in areas of the striatum in which areal density of PPE mRNA-containing cells was markedly decreased compared with control subjects, suggesting that a population of neurons actively expressing PPE mRNA survives in the brain of patients with HD despite progressive neuronal loss.

Although our results do not exclude the possibility that PPE mRNA is expressed in HD brains by neurons that do not normally express this mRNA, the results from patients with symptomatic and presymptomatic HD are consistent with the conclusion that enkephalinergic striatal neurons pass through a phase in which abnormalities of neurotransmitter metabolism, axonal transport, or terminal structure occur before cell death. This information may be of value in attempting to understand the pathogenesis of cell death in patients with HD. These findings also have implications for attempts to treat patients with $\mathrm{HD}$. A therapy that interferes with the basic mechanism of cell death in patients with HD may result in rescue of dysfunctional neurons and actually reverse rather than merely halt the progression of $\mathrm{HD}$.

We thank Dr S. Sabol for the gift of preproenkephalin cDNA. This study was supported by Public Health Service Grants BNS8616841, NS29230, and MH-44894 (M.-F.C.), NS-01300, NS-19613, NS-15655, and AG-08671.

\section{References}

1. Ferrante RJ, Kowall NW, Beal MF, et al. Selective sparing of a class of striatal neurons in Huntington's disease. Science 1985; 230:561-564

2. Dawbarn D, Dequidt ME, Emson PC. Survival of basal ganglia neuropeptide $\mathrm{Y}$-somatostatin neurones in Huntington's disease. Brain Res 1985;340:251-260
3. Ferrante RJ, Beal MF, Kowall NW, et al. Sparing of acerylcholinesterase-containing striatal neurons in Huntington's disease. Brain Res 1987;411:162-166

4. Hirsch EC, Graybiel AM, Hersh LB, et al. Striosomes and extrastriosomal matrix contain different amounts of immunoreactive choline aceryltransferase in the human striatum. Neurosci Lett 1989;96:145-150

5. Spokes EGS. Neurochemical alterations in Huntington's disease. Brain 1980;103:179-210

6. Beckstead RM, Cruz CJ. Striatal axons to the globus pallidus, entopeduncular nucleus and substantia nigra come mainly from separate cell populations in cat. Neuroscience 1986;19:147158

7. Parent A, Bouchard C, Smith Y. The striatopallidal and striatonigral projections: two distinct fiber systems in primates. Brain Res 1984;303:385-390

8. Parent A, Smith Y, Filion M, et al. Distinct afferents to internal and external pallidal segments in the squirrel monkey. Neurosci Lett 1989;96:140-144

9. Feger J, Crossman AR. Identification of different subpopulations of neostriatal neurones projecting to globus pallidus or substantia nigra in the monkey: a retrograde fluorescence double-labelling study. Neurosci Lett 1984;49:7-12

10. Gimenez-Amaya JM, Graybiel AM. Compartmental origins of the striatopallidal projection in the primate. Neuroscience 1990;34:111-126

11. Selemon LD, Goldman-Rakic PS. Topographic intermingling of striatonigral and striatopallidal neurons in the rhesus monkey. J Comp Neurol 1990;297:359-376

12. Anderson $\mathrm{KD}$, Reiner $\mathrm{A}$. Extensive co-occurrence of substance $P$ and dynorphin in striatal projection neurons: an evolutionary conserved feature of basal ganglia organization. J Comp Neurol 1990;295:339-369

13. Graybiel AM. Neurotransmitters and neuromodulators in the basal ganglia. Trends Neurosci 1990;13:244-254

14. Reiner A, Albin RL, Anderson KD, et al. Differential loss of striatal projection neurons in Huntington's disease. Proc Natl Acad Sci USA 1988;85:5733-5737

15. Albin RL, Young AB, Penney JB, et al. Abnormalities of striatal projection neurons and $N$-methyl-D-aspartate receptors in presymptomatic Huntington's disease. N Engl J Med 1990;322: 1293-1298

16. Ferrante RJ, Kowall NW, Harrington K, et al. Terminal striatal substance $\mathrm{P}$ - and metenkephalin-projections in the globus pallidus are equally affected in Huntington's disease. Soc Neurosci Abstr 1990;16:1120 (Abstract)

17. Vonsartel J-P, Meyers RH, Stevens TJ, et al. Neuropathological classification of Huntington's disease. J Neuropathol Exp Neurol 1985;44:559-577

18. Chesselet M-F. In situ hybridization histochemistry. Boca Raton, FL: CRC Press, 1990:189-193

19. Yoshikawa K, Williams C, Sabol S. Rat brain preproenkephalin mRNA: cDNA cloning, primary structure and distribution in the central nervous system. J Biol Chem 1984;259:1430114308

20. Maniatis T, Fritsch EF, Sambrook J. Molecular cloning: a laboratory manual. New York: Cold Spring Harbor Laboratory, 1982

21. Mercugliano M, Chesselet M-F. Effects of clozapine and haloperidol on striato-pallidal neurons as revealed by in situ hybridization histochemistry in the rat. Neurosci Abstr 1990;16:1232 (Abstract)

22. Chesselet M-F, Weiss LT, Wuenschell $C$, et al. Comparative distribution of mRNAs for glutamic acid decarboxylase, tyrosine hydroxylase and tachykinins in the basal ganglia: an in situ hybridization study in the rodent brain. J Comp Neurol 1987; 262:125-140

23. Salin P, Mercugliano M, Chesselet M-F. Differential effect 
of chronic haloperidol and clozapine on preprosomatostatin mRNA in the striatum, nucleus accumbens and frontal cortex of the rat. Cell Mol Neurobiol 1990;1:127-140

24. Siegel S. Nonparametric statistics for the behavioral sciences. New York: McGraw-Hill, 1956:127-131

25. Ferrante RJ, Kowall NW, Richardson EP, Bird ED: Topography of enkephalin, substance $P$ and acetylcholinesterase staining in Huntington's disease striatum. Neurosci Lett 1986;71:283-288

26. Hedreen JC, DeLong MR. Organization of striatopallidal, striatonigral and nigrostriatal projections in the macaque. J Comp Neurol 1991 (in press)

27. Reisine TD, Fields JZ, Stern LZ, et al. Alterations in dopaminergic receptors in Huntington's disease. Life Sci 1978;21:11231128
28. Perry RH, Candy JM, Perry EK, et al. Extensive loss of choline acetyltransferase activity is not reflected by neuronal loss in the nucleus of Meynert in Alzheimer disease. Neurosci Lett 1982;33:311-315

29. Beal MF, Mazurek MF, Ellison DW, et al. Somatostatin and neuropeptide $\mathrm{Y}$ concentrations in pathologically graded cases of Huntington's disease. Ann Neurol 1988;23:562-569

30. Normand E, Popovici T, Fellman D, et al. Anatomical study of enkephalin gene expression in the rat forebrain following haloperidol trearment. Neurosci Lett 1987;83:232-236

31. Tang F, Costa E, Schwartz JP. Increase of proenkephalin mRNA and enkephalin content of rat striatum after daily injection of haloperidol for 2 to 3 weeks. Proc Natl Acad Sci USA 1983; $80: 3841-3844$ 